\title{
OBESITY AND INSULIN RESISTANCE IN CHILDHOOD
}

\author{
Dalibor Pastucha ${ }^{1}$, Jana Malinčíková1, Jiří Hyjánek², Dagmar Horáková3 , Luděk Čižek ${ }^{3}$, Gabriela Janoutová3, \\ Vladimír Janout ${ }^{3}$ \\ ${ }^{1}$ Clinic for Rehabilitation and Movement Medicine, Faculty of Medicine, Palacky University, Olomouc, Czech Republic \\ 2Department for Medical Genetics and Fetal Medicine, Faculty of Medicine, Palacky University, Olomouc, Czech Republic \\ ${ }^{3}$ Department of Preventive Medicine, Faculty of Medicine, Palacky University, Olomouc, Czech Republic
}

\section{SUMMARY}

Obesity is a serious risk factor for insulin resistance leading to diabetes and other disorders. As it is also occurring at ever younger age groups the aim of this study was to compare average levels of the homeostatic indices HOMA and QUICKI in obese compared to healthy children in an effort to find convenient markers for insulin sensitivity in clinical pediatric practice. Twenty one obese and 29 healthy children were selected. The average level of HOMA in obese children was 3,6, in healthy children 1,7 while the average level of QUICKI in obese children was 0,33 and in healthy children 0,36 . The results demonstrate the possibility of insulin sensitivity assessment using these indices in pediatric practice. QUICKI has a narrower confidence interval and thus lower variability.

Key words: obesity in children, insulin resistance, HOMA, QUICKI

Address for correspondence: D. Pastucha, Clinic for Rehabilitation and Movement Medicine, Faculty of Medicine, Palacky University, Olomouc, I. P. Pavlova 6, 77520 Olomouc, Czech Republic. E-mail: pastuchad@fnol.cz

\section{INTRODUCTION}

In recent years, ever increasing numbers of children in the Czech Republic are manifesting the first signs of disorders which earlier were only seen predominatly in adults, as for example, high blood pressure and the insulin resistence syndrome leading to diabetes type 2 (DT2). These illnesses are connected to risk factors, one of which is overweight or obesity. Obesity itself need not always mean overweight but an accumulation of fatty tissue. In childhood it is obvious that the continuous increase in weight is not merely caused by increasing fat tissue but development of the body frame and muscle mass. The share of this component differs according to the individual age group and gender.

Obesity in children in the Czech Republic is a serious epidemiological problem: $20 \%$ of children aged $6-12$ and $11 \%$ of children aged 13-17 years are already overweight or obese. These data were provided by the the study of the Czech Obesity Association entitled "Life style and obesity 2005". The childhood population in the Czech Republic was divided according to age into two groups: 6-12 years and 13-17 years. In the first group $10 \%$ of children were overweight and $10 \%$ were obese. The highest proportion of children with obesity (18\%) was in children aged 7 years just close to the beginning of school attendance and related life style changes. In adolescence, the data in contrast, are more favourable: from 13-17 years the proportion of overweight children fell to $6 \%$ and $5 \%$ of children were obese. Obesity naturally is one of the most important risk factors for the development of insulin resistance and other disease conditions which are connected with this syndrome (1).
The aim of this study was to determine average levels of the homeostatic indices HOMA and QUICKI, in a group of obese children compared to a group of healthy children and to assess the value of these indices for predicting the development of insulin resistance.

\section{MATERIAL AND METHODS}

Twenty one obese boys of average age 16,5 years, who were receiving advice on losing weight at the Department of Clinical Psychology, Faculty Hospital in Olomouc formed the patient group. Another 29 children (24 boys and 5 girls) of average age 16.2 years who showed normal physiological parameters were used as the control group of healthy children. In each child the following were measured: blood pressure, body mass index (BMI) and laboratory concentrations of total cholesterol, triacylglycerols, HDL and LDL cholesterol, glycemia and insulinemia. The values of glucose and insulin concentration were used to calculate homeostatic indices, HOMA and QUICKI.

The homeostatisic index for insulin resistance, HOMA IR was calculated according to the homeostatic model $(2,3)$ as:

HOMA IR $=$ insulin fasting $(\mu \mathrm{IU} / \mathrm{ml}) \times$ glycemia fasting $(\mathrm{mmol} / \mathrm{l}) / 22,5$

Homeostatic index insulin resistance QUICKI was calculated according to Katz et al. (4)

QUICKI $=1 / \log$ insulin fasting $(\mu \mathrm{IU} / \mathrm{ml})+\log$ glycemia fasting $(\mathrm{mg} / 100 \mathrm{ml})$ or 
QUICKI $=1 /[\log$ insulin fasting $(\mu \mathrm{IU} / \mathrm{ml})+\log$ glycemia fasting $(\mathrm{mmol} / \mathrm{l}) \times 18.182]$

Insulin resistance is defined as values of HOMA index greater than or equal to 2.68 and QUICKI as values less than or equal to 0.34 .

Statistical evaluation was done using the programme Statistics version 6.0.

\section{RESULTS}

In Table 1 the results for examination in the control group of children as means and SD are shown. Results could be calculated as physiological parameters for each followed value. In Table 2 the results for the obese group for each parameter are presented. Individuals in this group also showed normal physiological values. Only insulin resistance was higher.

In Figs. 1 and 2 mean values for homeostatic indices with their $95 \%$ confidence intervals are depicted. Figure 1 shows mean values for the HOMA index in healthy children was 1,7 while in obese children it was 3.6. Figure 2 shows mean values for QUICKI in healthy children was 0.36 while in obese children it was 0.33. Values for QUICKI in obese children may indicate the shift toward insulin resistance. From Figs. 1 and 2 it seems clear that levels of both groups are different, because confidence intervals do not overlap.

Table 1. Parameters in healthy children

\begin{tabular}{|l|c|c|}
\hline Parameters & Mean & Standard deviation \\
\hline Cholesterol & 3.681 & 0.606 \\
\hline HDL & 1.319 & 0.214 \\
\hline LDL & 1.902 & 0.572 \\
\hline TAG & 1.014 & 0.376 \\
\hline Glycemia & 4.950 & 0.340 \\
\hline Inzulinemia & 7.693 & 4.112 \\
\hline BMI percentile & 48.367 & 23.818 \\
\hline HOMA & 1.709 & 0.987 \\
\hline QUICKI & 0.360 & 0.028 \\
\hline
\end{tabular}

Table 2. Results in obese children

\begin{tabular}{|l|c|c|}
\hline Parameters & Mean & Standard deviation \\
\hline Cholesterol & 4.063 & 0.674 \\
\hline HDL & 1.266 & 0.300 \\
\hline LDL & 2.260 & 0.875 \\
\hline TAG & 1.366 & 0.848 \\
\hline Glycemia & 4.890 & 0.462 \\
\hline Inzulinemia & 15.620 & 8.261 \\
\hline BMI percentile & 97.533 & 2.705 \\
\hline HOMA & 3.604 & 1.866 \\
\hline QUICKI & 0.327 & 0.029 \\
\hline
\end{tabular}

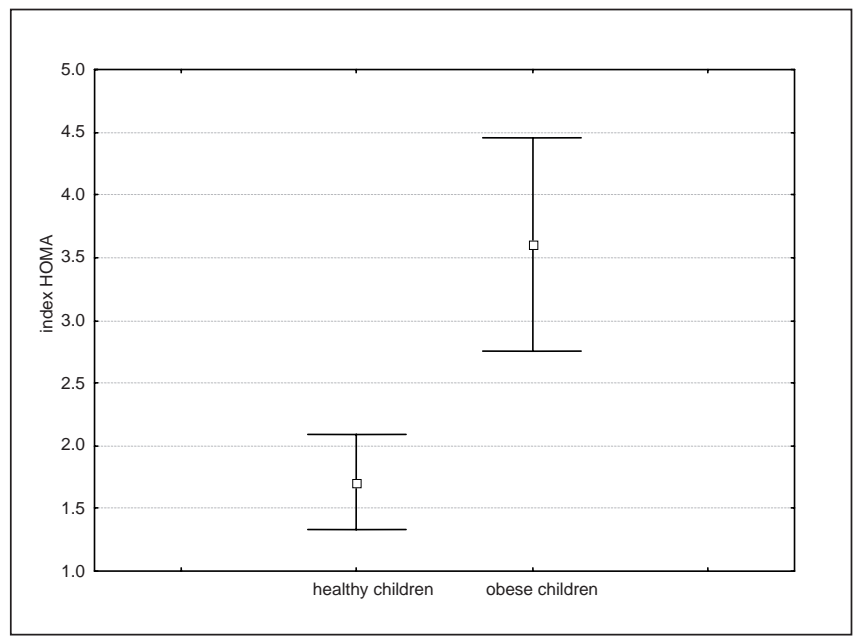

Fig. 1. Means and $95 \%$ confidence intervals of HOMA.

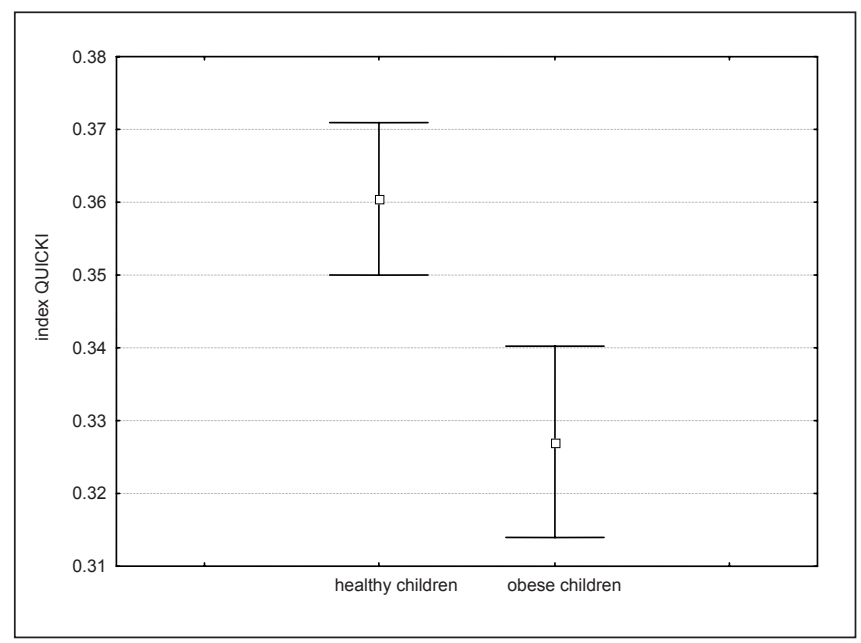

Fig. 2. Means and 95\% confidence intervals of QUICKI.

\section{DISCUSSION}

Methods currently used for the diagnosis of insulin resistance are very demanding to carry out and completely unsuited to the investigation of large numbers of people. Other approaches are therefore sought such as the easy to assess homeostatic relations between insulin and glycemia. Increase in concentration of insulin can be in physiological terms guide to glycemia and vice versa. Disorders in this relationship show insufficient activity of insulin and are the basis of the homeostatic model used to appraise insulin resistance. Among indices and results the "clamping technique" has repeatedly verified the highly significant correlation $(5,6)$

In Table 1, it can be seen that the mean value for the HOMA index which can characterise insulin resistance in healthy nonobese children of mentioned age is $1.7 \pm 0.98$ while the QUICKI value in these children is $0.36 \pm 0.02$. These values can be considered as standard for healthy children (7).

Obesity in adolescence may be a result of growth in infantile age. The majority of studies on infant size have shown that infants who were recognised as "obese" or who were in the higher range of body mass index, were more inclined to the development of obesity in childhood, adolescence or early adulthood than other children. Infants who grew quickly were more inclined to obesity 
in childhood, puberty and early adulthood than other children as well. Large size or rapid phase of growth in the intervals between the first and second year of life are predictive of an inclination to later obesity (8). In a group of obese children changed HOMA and QUICKI indices which were signs of the possible development of insulin resistence, were found even though at the current moment no demonstrable increase in other metabolic parameters apart from insulinemia was detected. If these children experienced negative changes in metabolic parameters, the development of insulin resistance could in the near future be accelerated.

\section{CONCLUSIONS}

The results show the possibility of evaluating insulin sensitivity from levels of glycemia and insulinemia with the help of the homeostatic indicies HOMA and QUICKI, for use in pediatric practice. In reality, index QUICKI which has narrower confidence intervals and hence less variability may be more useful. Healthy children have values of QUICKI index around 0.36. Obese children have lower values.

\section{REFERENCES}

1. Ministry of Health of the Czech Republic [homepage on the Internet]. Prague: Ministry of Health CR [cited 2007 Jun 4]. Kunešová M. Lifestyle and obesity in the Czech Republic. Available from: http://www. mzcr.cz/print.php?clanek=2038. (In Czech.)

2. Haffner SM, Miettinen H, Stern MP. The homeostasis model in the San Antonio Heart Study. Diabetes Care. 1997 Jul;20(7):1087-92.

3. Matthews DR, Hosker JP, Rudenski AS, Naylor BA, Treacher DF, Turner RC. Homeostasis model assessment: insulin resistance and $\beta$-cell function from fasting plasma glucose and insulin concentrations in man. Diabetologia. 1985 Jul;28(7):412-9.

4. Katz A, Nambi SS, Mather K, Baron AD, Follmann DA, Sullivan G, et al. Quantitative insulin sensitivity check index: a simple, accurate method for assessing insulin sensitivity in humans. J Clin Endocrinol Metab. 2000 Jul;85(7):2402-10

5. Bonora E, Targher G, Alberiche M, Bonadonna RC, Saggiani F, Zenere $\mathrm{MB}$, et al. Homeostasis model assessment closely mirrors the glucose clamp technique in the assessment of insulin sensitivity: studies in subjects with various degrees of glucose tolerance and insulin sensitivity. Diabetes Care. 2000 Jun;23(1):57-63.

6. Hřebíček J, Janout V, Malinčíková J, Horáková D, Čížek L. Detection of insulin resistance by simple quantitative insulin sensitivity check index QUICKI for epidemiological assessment and prevention. J Clin Endocrinol Metab. 2002 Jan;87(1):144-7.

7. Malinčíková J, Horáková D, Čížek L, Wiedermann J, Kopecký M, Janout V. Insulin resistance in children and adolescents. Cesk Pediatr. 2007;62(4):213-9. (In Czech.)

8. Baird J, Fisher D, Lucas P, Kleijnen J, Roberts H, Law C. Being big or growing fast: systematic review of size and growth in infancy and later obesity. BMJ. 2005 Oct 22;331(7522):929.

Received June 6, 2007 Received and accepted June 11, 2007 